$$
\begin{gathered}
\text { 이례상황 스트레스에 따른 심리적 피로가 안전행동과 사고에 } \\
\text { 미치는 영향: } \\
\mathrm{A} \text { 지하철 기관사를 중심으로 } \\
\text { 김 승 태" }{ }^{*} \text { 신 택 현 }{ }^{*} \text { 이 용 만 } \cdot \text { 구 승 환 } \\
\text { "서울과학기술대학교 }
\end{gathered}
$$

\title{
The Effect of Psychological Fatigue Caused by Emergency Stress on Safety Behavior and Accidents: Focused on the Subway Train Drivers
}

\author{
Seung-Tai Kim ${ }^{*} \cdot$ Tack-Hyun Shin ${ }^{*} \cdot$ Yong-Mann Lee* ${ }^{*}$ Seung-Hwan Gu*
}

${ }^{*}$ Seoul National University of Science and Technology

\begin{abstract}
This study highlights the theme of human error of train drivers, conducting empirical analysis on the relationship between emergency stress, psychological fatigue, safety behavior, and accident. The hypothetical test results based on questionnaires received from 223 train drivers working at A subway firm indicate that emergency stress shows a significant positive effect on psychological fatigue, which in turn shows a significant negative influence on safety behavior. And safety behavior is shown having a significant negative relationship with accident. These results suggest the necessity of corporate-level approaches to depict the drastic causes of drivers' emergency stress, and to effectively manage this stress, as well as the necessity of making effort to enhance safety behavior, and to prevent or reduce accidents.
\end{abstract}

Keywords : Psychological Fatigue, Emergency Stress, Safety Behavior, Accidents, Train Driver

1. 연구배경

기관사는 안전업무 종사자(Safety-Critical Worker) 로서 이들의 직무는 시간적 압박이 매우 높으며 인적 오류 발생확률이 높다[1]. 이 같은 직무특성으로 인해 기관사는 일상적으로 다양한 스트레스 환경에 노출되 어 있으며, 이에 따른 정신적, 신체적 피로는 안전행동 과 사고에 직접 혹은 간접적으로 부정적 영향을 미칠 개연성이 높다. 본 연구는 그 동안 다양한 반복 연구가 이루어진 철도기관사의 스트레스를 주요 구성개념으로 설정하되 특히 기관사가 경험하는 이례상황 스트레스
(Emergency Stress)가 심리적 피로, 안전행동 및 사고 에 미치는 영향을 실증적으로 접근하여 시사점을 밝히 는 것을 주요 목적으로 삼았다.

\section{2. 선행연구 고찰 및 연구가설}

기관사의 스트레스 유발요인은 매우 다양하지만 직 무수행과 관련한 스트레스는 크게 이례상황 스트레스, 교번근무 등 제도관련 스트레스, 신체물리 스트레스, 1 인 승무 스트레스 및 업무구간 미숙지 스트레스로 구 분될 수 있다[2].

† 이 연구는 서울과학기술대학교 교내연구비의 지원으로 수행되었습니다.

† Corresponding author : Tack-Hyun Shin, Seoul National University of Science and Technology M • P : 010-4201-6468, E-mail : shin6468@seoultech.ac.kr

Received January 20, 2014; Revision Received March 12 , 2014; Accepted March 12 , 2014. 
이례상황이란 예기치 못한 사고나 장애 발생에 직면 하여 정확하고 신속한 판단을 토대로 조치를 취해야 하는 비상상황 혹은 위급상황을 의미하는 것으로, 대부 분의 기관사는 이 같은 상황에 직면할 경우 극심한 불 안과 압박감을 느끼게 된다.

이례상황 스트레스는 이처럼 이례상황에 봉착한 시 점뿐만 아니라 정상적인 운전상황에서도 유발될 수 있 는데, 이 같은 이례상황이 언제 자신에게 닥칠지 모른 다는 우려로 인한 불안과 이례상황시 효과적인 대처에 실패했을 때 돌아올 처벌과 불이익에 대한 우려감, 즉 예기불안 스트레스가 그것이다. 이 같은 예기불안 스트 레스 이외에도 이례상황은 기관사의 인지과정과 신체 적 반응에도 영향을 미치게 된다. 따라서 현직기관사와 의 인터뷰 결과에 토대해 인지과정과 신체반응까지 감 안한 스트레스 유발요인을 정리하면 <Table 1 >과 같 다. 특히 과거에 사상 사고나 아차사고의 경험이 있는 기관사라면 이 같은 이례상황 스트레스는 더욱 가중될 수밖에 없다[3].

<Table 1> 이례상황과 스트레스

\begin{tabular}{|c|c|}
\hline 범주 & 스트레스 유발 요인 \\
\hline \multirow{5}{*}{$\begin{array}{l}\text { 예기 } \\
\text { 불안 } \\
\text { 스트 } \\
\text { 레스 }\end{array}$} & 1. 향후의 인명사고/장애 발생가능성 불안 \\
\hline & 2. 이례상황시 책임/불이익의 우려감 \\
\hline & 3. 이례상황시 미숙지 규정 및 사규 존재 불안감 \\
\hline & 4. 이례상황시 규정/수칙에 부합한 조치여부 불안 \\
\hline & 5. 이례상황시 기기오작동의 불안감 \\
\hline \multirow{6}{*}{$\begin{array}{l}\text { 인지 } \\
\text { 스트 } \\
\text { 레스 }\end{array}$} & 1. 정시성과 승객안전의 기준갈등 강박 \\
\hline & 2. 일상적 다중판단과 집중력 유지 애로 \\
\hline & 3. 이례상황시 정확/신속판단 애로 \\
\hline & 4. 이례상황시 다중판단 및 지시사항 스트레스 \\
\hline & 5. 이례상황시 조기종료 압박감 \\
\hline & 6. 신속/정확판단 요구상황시 규정과 지시 혼동 \\
\hline \multirow{2}{*}{$\begin{array}{l}\text { 정서 } \\
\text { 스트 } \\
\text { 레스 }\end{array}$} & 1. 이례상황시 당황/긴장 \\
\hline & 2. 이례상황시 식은땀 \\
\hline
\end{tabular}

Source: J.Y.Yoon (2013) [2]

초기의 선행연구들에 따르면 스트레스가 사고에 직 접적인 영향을 준다는 가설을 수립할 수 있다. 하지만 근래에 이르러 스트레스와 사고간의 관계를 밝힌 수많 은 후속연구들은 스트레스가 사고유발의 개연성을 높 인다는 점에선 견해가 일치하지만, 스트레스와 사고 간 의 직접적 관계보다는 둘 사이에 존재하는 매개변인의 발굴과 이들이 사고에 미치는 영향을 실증적으로 밝혀 오고 있다. 따라서 본 연구에서는 이례상황 스트레스와 사고간의 직접적인 관계는 고려하지 않기로 한다.
이례상황 스트레스를 포함한 모든 스트레스는 대부 분 신체적, 정신적으로 다양한 부정적 결과를 야기하는 데, 스트레스가 장기화될 경우 피로, 천식, 두통, 부정 맥, 소화불량, 궤양 등의 증세가 나 타나며 면역체계 에 손상이 발생하는 것으로 보고되고 있다[4].

기존의 선행연구들은 피로의 주원인으로 스트레스와 수면 장애(sleep disorder)를 들고 있대[5]. 또한 직무소진(job burnout)을 주제로 한 최근의 연구들에 의하면 조직구성원 이 느끼는 정서적 탈진상태(a state of emoti onal exhaus tion), 탈개인화 현상(depersonalization of individuals) 및 낮 은 성취감(feelings of low accom plishment) 등의 심리적 피로현상은 바로 직무스트레스로 인한 무력감에서 나타나는 부정적 현상임을 보고하고 있다[6].

이 같은 논의에 토대할 때 다음과 같은 가설을 설정 할 수 있다.

[가설 1] 이례상황 스트레스의 증가는 기관사의 심리 적 피로도에 정(+)의 영향을 미칠 것이다.

또한 스트레스와 안전행동(혹은 사고)과의 관계를 밝 힌 연구도 존재한다. 이들 연구에 의하면 스트레스가 오류율을 높이고, 인지실수가 높은 사람일수록 연속적 인 외부스트레스에 취약하다. 트럭과 승용차 운전자를 대상으로 한 연구에서는 연령, 성별 및 스트레스가 사 고와 위반보고의 $35 \%$ 를 설명하는 것으로 나타났는데 [7], 이 연구결과는 스트레스와 사고의 직접적 관계보 다는 스트레스로 인한 사고 및 오류유발의 개연성을 강조한 연구로 볼 수 있다. 이와 함께 스트레스는 반응 시간이나 판단과 같은 지적인 수행능력을 감소시켜 이 로 인해 오류가능성이 증대되며 궁극적으로 사고를 유 도할 수 있다는 연구도 있다[8]. 이 같은 논의에 토대 할 때 다음과 같은 가설을 설정할 수 있다.

[가설 2] 이례상황 스트레스의 증가는 기관사의 안전 행동 수준에 부(-)의 영향을 미칠 것이다.

다음으로 피로와 안전행동 간의 관계를 살펴보면, 피 로는 과업수행자의 수행능력과 수행동기를 감소시키고 사고위험성을 증대시키는 요인으로 특히 심리적 피로 는 냉담과 무관심을 유발하며 안전에 대해 무감각한 상태를 초래할 가능성이 높다[9]. 도로운전자를 대상으 로 한 일부 연구에 의하면 피로는 이례상황에서 반응 시간 지연, 주의력 저하 및 정보처리능력 저하현상을 초래하며[10], 다른 연구에서도 피로는 조심성, 주의력, 의사결정능력 및 인지능력의 저하를 유발시키는 주요 인인 것으로 보고되었다[11]. 결국 피로는 안전행동의 
저하를 가져오고 궁극적으로 사고로 연결될 개연성을 높인다고 할 수 있다. 이 같은 논의에 토대할 때 다음 과 같은 가설을 설정할 수 있다.

[가설 3] 기관사의 심리적 피로도 증가는 안전행동에 부(-)의 영향을 미칠 것이다.

한편, 안전행동과 사고간의 관계를 검증한 대부분 연 구들은 이들 두 변인 간에 매우 유의한 부(-)의 관계가 있으며[12], 특히 집단수준에서의 안전행동은 사고를 예측할 수 있는 강력한 선행변인임을 보고하고 있다 [13]. 국내연구로 KTX 기장을 대상으로 한 가장 최근 의 연구에서도 기기취급 오류(즉 실수, mistake) 경험 이 아차사고 및 책임사고와 유의한 정(+)의 관계가 있 는 것으로 밝혀졌는데, 실수는 안전행동의 한 가지 하 위차원이라는 점에서 이 연구는 안전행동과 사고간의 관계를 실증적으로 입증한 연구라고 할 수 있겠다[14].

이 같은 논의에 토대할 때 다음과 같은 가설을 설정 할 수 있다.

[가설 4] 기관사의 안전 준수와 사고 간에는 부(-)의 관계가 있을 것이다.

마지막으로 본 연구에서는 가설을 설정하진 않지만 추 가적으로 매개변인간의 직접효과와 간접효과를 분석하여 모든 구성개념간의 총합적 관계 및 총 효과를 살펴봄으 로써 좀 더 의미 있는 시사점을 도출하고자 하였다.

\section{3. 연구 설계}

\section{1 연구모형과 척도}

선행연구들이 밝힌 논의와 함의들을 종합하여 본 연 구에서는 [Figure 1]과 같은 연구모형을 제시하였다. 즉 주요 구성개념인 이례상황 스트레스, 심리적 피로, 안전행동 및 사고간의 인과관계를 가설검증을 통해 밝 히고자 하는 것이 본 연구의 목적이다. 이례상황 스트 레스에 관한 설문은 윤준영(2013)의 연구[2], 심리적 피 로와 안전행동에 관한 설문은 박영석(2011)의 연구[9] 를 토대로 하였고, 사고변인은 본인의 과실에 의한 사 고경험 유무(예/아니오)를 이항변수(binary variable), 즉 Dummy변수로 전환하여 활용하였다.

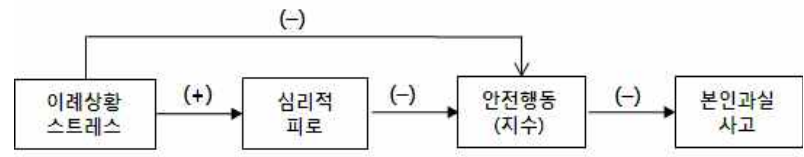

[Figure 1] The Model of the Study

본 연구에서 활용된 안전행동 변인은 박영석의 연구[9] 에 따라 안전행동을 구성하는 네 가지 하위변인인 준수 및 습관(이상 안전행동), 실수 및 위반(이상 불안전행동) 을 아래의 산식에 의해 안전행동지수(Safety Behavior Index)라는 새로운 변인으로 전환하여 사용하였다.

안전행동지수 $=$ 안전행동 $\div($ 불안전행동 + 안전행동 $)=$ (준수 + 습관 -2$) \div($ 실수 + 위반 + 준수 + 습관 -4$)$

안전행동지수는 준수, 습관, 위반 및 실수 등 안전과 관련된 네 가지 행동 중 안전행동의 비율이 어느 정도 인지를 보여주는 지표로 가장 이상적인 안전지수는 1 이며, 일반적으로 $0 \sim 1$ 사이의 값을 지니게 된다.

\section{2 응답자 특성}

2012년 11-12월 중 서울의 도시철도기관인 $\mathrm{A}$ 조직의 철도기관사로부터 총 223 부의 설문지를 수거하여 통계 처리의 대상으로 삼았다. 설문응답자의 분포를 살펴보 면 응답자 중 남성이 220명, 여성 3명이었고, 연령대는 50세 이상이 17명, 40-49세가 140명, 30-39세가 52명, 20 대가 11 명이었으며, 학력은 고졸 31 명, 전문대졸 75 명, 대졸이상 113 명이었다. 그리고 본인과실사고 경험 자는 43 명인 것으로 집계되었다. 응답자 특성은 $<$ Table 2>와 같다.

$<$ Table 2> Demography of the Respondents

\begin{tabular}{|c|c|c|c|}
\hline Factor & Category & Freq. & $\%$ \\
\hline \multirow{4}{*}{ Age } & $20 \sim 29$ & 11 & 4.9 \\
& $30 \sim 39$ & 52 & 23.3 \\
& $40 \sim 49$ & 140 & 62.8 \\
& Over 50 & 17 & 7.6 \\
& N/A & 3 & 0.1 \\
\hline \multirow{4}{*}{ Education } & High School & 31 & 13.9 \\
& 2 Yr. College & 75 & 33.6 \\
& Over Yr. Univ. & 113 & 50.7 \\
Job Grade & N/A & 4 & 0.2 \\
& $4-5$ & 114 & 51.1 \\
& $6-7$ & 91 & 40.8 \\
& $8-9$ & 17 & 7.6 \\
Working & N/A & 1 & 0.004 \\
\hline Years as & $1-10$ & 86 & 38.6 \\
driver & $11-20$ & 128 & 57.4 \\
& 21 30 & 11 & 4.9 \\
Experience of & More than 31 & 24 & 10.8 \\
accident & N/A & 3 & 0.1 \\
by own fault & Yes & 156 & 80.9 \\
\hline & No & 24 & 10.8 \\
\hline
\end{tabular}




\section{4. 연구결과}

\section{1 측정도구의 타당성 검증 및 확인적 요 인분석}

본 연구에 포함된 구성개념들은 해당 항목내용에 대 한 동의 정도를 측정하는 다항목척도인 리커트 5점 척 도(Likert 5 scale)를 활용하였다. 수거된 223부의 설문 중 결측치를 제거한 최종 유효설문은 총 223 부였고, 이 를 대상으로 측정항목의 타당성을 검증하기 위하여 $\mathrm{AMOS} 20.0$ 을 활용하여 확인적 요인분석을 실시하였다.

확인적 요인분석에 앞서 외생변인인 이례상황 스트 레스와 내생변인인 심리적 피로는 설문을 통해 복수문 항으로 측정이 가능하나 지수(index)로 전환된 안전행 동과 사고는 단일문항인 만큼 척도로서의 한계가 존재 한다. 따라서 이를 분석하기 위해 단일지표의 추정치를 사용하였다. 단일지표의 추정치는 0.7 또는 0.8 을 사용 하는 것이 일반적이기 때문에 본 연구에선 최소한의 수치라 할 수 있는 0.7 을 사용하여 분석하였다. 단일 지표를 설정하는 가장 일반적인 방법은 요인적재량을 1 로 두고, 측정오차는 $(1-\alpha) \sigma^{2}$ 으로 고정시키는 것이 라 할 수 있는데[15][16], 이렇게 하면 추정의 결과가 명확하고, 요인적재량이 불편추정치가 되기 때문에 측 정 문항의 결함을 극복할 수 있다.

확인적 요인분석에서 중요한 것은 적합도의 적용인
데 이를 엄격하게 적용할 경우 RMSEA(root mean square error of approximation)은 0.08이하, GFI (good ness-of-fit-index), NFI(normed fit index), CFI (compa rative fit index)는 0.9이상, AGFI(adjusted goodness -of-fit-index)는 0.8이상 되어야 한다고 보고 있다[17]. 따라서 기본 모형의 적합도가 해당 기준을 충족시키지 못할 경우 본 연구에서는 타당성을 저해하는 항목을 제거하였다. <Table $3>$ 은 타당성을 저해하는 항목을 제 거한 후의 모형적합도 지수를 나타낸 것이다. 적합도 지 수는 $=111.996(\mathrm{df}=61, \mathrm{p}=0.000), \quad x^{2} / \mathrm{df}=1.836, \quad \mathrm{RMSEA}=$ 0.061, GFI $=0.928$, AGFI $=0.892, \quad \mathrm{IFI}=0.971, \mathrm{NFI}=0.939$, $\mathrm{CFI}=0.971$ 로 나타났으며, 표본크기에 민감한 $x^{2}$ 값을 제 외하고는 수용할만한 수준이라 할 수 있다. 본 모형에서 표준화된 적재치는 모두 0.5 이상으로 나타났기 때문에 개념타당성은 확보되었다고 할 수 있으며, 개별 측정변 수들의 각 개념의 신뢰도는 0.8 이상으로 나타났기 때문 에 수렴타당성도 확보되었다고 할 수 있겠다. 그리고 측 정 모형의 판별타당성을 분석하기 위해 연구 단위들의 AVE(Average Variance Extracted: 평균분산추출지수) 와 상관계수 값을 비교해본 결과 $\langle$ Table $4>$, 두 요인 사 이의 $\mathrm{AVE}$ 가 각 요인의 상관계수의 제곱보다 크게 나타 났기 때문에 판별타당성이 확보되었다. 마지막으로 변수 의 내용타당성 분석을 위해 내적일관성 분석을 수행한 결과 Cronbach $\alpha$ 값이 0.7 이상으로 나타나 내용타당성도 만족시키고 있음을 확인하였다.

$<$ Table $3>$ Result of CFA

\begin{tabular}{|c|c|c|c|c|c|c|c|}
\hline Construct & $\begin{array}{l}\text { Measurement } \\
\text { Items }\end{array}$ & $\begin{array}{l}\text { Standardized } \\
\text { Loading }\end{array}$ & S.E & $\mathrm{t}$-value & $\begin{array}{l}\text { 개념 } \\
\text { 신뢰도 }\end{array}$ & AVE & $\alpha$ \\
\hline \multirow{5}{*}{$\begin{array}{c}\text { Emergency } \\
\text { Stress }\end{array}$} & Embarrassed and anxious & .810 & - & - & \multirow{5}{*}{.918} & \multirow{5}{*}{.691} & \multirow{5}{*}{.890} \\
\hline & Difficulty in fast judgment & .806 & .070 & 13.386 & & & \\
\hline & Cold sweat & .793 & .081 & 12.799 & & & \\
\hline & Tension of solitary driving & .750 & .083 & 11.992 & & & \\
\hline & Anxiety of exit door broke / overrun & .782 & .077 & 12.339 & & & \\
\hline \multirow{6}{*}{$\begin{array}{c}\text { Psychological } \\
\text { Fatigue }\end{array}$} & Frustration & .879 & - & - & \multirow{6}{*}{.948} & \multirow{6}{*}{.726} & \multirow{6}{*}{.930} \\
\hline & Emotional exhaustion & .913 & .055 & 20.276 & & & \\
\hline & Life battered with fatigue & .854 & .061 & 17.242 & & & \\
\hline & Worn-out & .848 & .058 & 16.983 & & & \\
\hline & Loss of concentration & .757 & .059 & 14.048 & & & \\
\hline & Fatigue of every morning & .724 & .066 & 12.993 & & & \\
\hline SBI & Safety Behavior Index & .550 & - & - & .980 & .980 & - \\
\hline Accident & accident by own fault & .546 & - & - & .866 & .866 & - \\
\hline
\end{tabular}

$x^{2}=111.996(\mathrm{df}=61, \mathrm{p}=0.000), x^{2} / \mathrm{df}=1.836, \mathrm{RMSEA}=0.061, \mathrm{GFI}=0.928$, AGFI=0.892, IFI=0.971, NFI=0.939, CFI=0.971, SBI: Safety Behavior Index, $\alpha$ : Cronbach Alpha Coefficient 
$<$ Table $4>$ Correlation Coefficient and AVE

\begin{tabular}{|c|c|c|c|c|}
\hline & $\begin{array}{c}\text { Emerge } \\
\text {-ncy } \\
\text { Stress }\end{array}$ & $\begin{array}{c}\text { Psychol } \\
\text {-ogical } \\
\text { Fatigue }\end{array}$ & SBI & $\begin{array}{c}\text { Accid } \\
\text {-ent }\end{array}$ \\
\hline \hline $\begin{array}{c}\text { Emergency } \\
\text { Stress }\end{array}$ & .691 & & & \\
\hline $\begin{array}{c}\text { Psychological } \\
\text { Fatigue }\end{array}$ & $.480^{* * *}$ & .726 & & \\
\hline SBI & $-.393^{* * *}$ & $-.525^{* * *}$ & .980 & \\
\hline Accident & .125 & -.053 & $-.228^{*}$ & .866 \\
\hline
\end{tabular}

$* * *=\mathrm{p}<0.001, * *=\mathrm{p}<0.01, *=\mathrm{p}<0.05$

\section{2 구조방정식 결과와 가설검증}

본 연구에서는 실증분석을 위해 구조방정식 모형을 활 용하였다. 연구모형으로 설정된 전체적인 구조모형을 검 정한 결과, $x^{2}=111.996(\mathrm{df}=63, \mathrm{p}=0.000), x^{2} / \mathrm{df}=$

1.892, RMSEA $=0.063, \mathrm{GFI}=0.924, \mathrm{AGFI}=0.890, \mathrm{IFI}=0.968$, $\mathrm{NFI}=0.935, \mathrm{CFI}=0.968$ 의 값을 갖는 모형이 도출되었다.

이러한 모형은 공분산 구조분석의 일반적인 평가지 표들과 비교해 볼 때 적절한 수준으로 판단되기에 모 형은 적합한 것임을 알 수 있다. 본 연구에서 설정한 구조모형 경로분석 결과는 <Table $5>$ 와 같고, 경로계 수에 대한 결과를 도식화하면 [Figure 2]와 같다.

본 연구에서는 매개변인간의 직접효과와 간접효과, 총 효과를 추가적으로 분석하였으며, 통계적 유의성 검 증을 위해 bootstrapping을 수행하였다. 간접효과 분석 결과 이례상황 스트레스와 안전행동지수 간에는 $-.035(\mathrm{p}=.003)$, 이례상황 스트레스와 사고 간에는 $.037(\mathrm{p}=.023)$, 심리피로와 사고 간에는 .037( $\mathrm{p}=.015)$ 의 간접효과 가 나타났다(비표준화계수 기준). 따라서 이례상황스트레 스는 안전행동지수와 사고에, 심리피로는 사고에 유의한 간접효과 및 총효과가 있는 것을 알 수 있었다.

이 같은 통계결과를 토대로 가설에 대한 검정을 수 행하면 다음과 같다.

가설 1 은 이례상황 스트레스의 증가가 기관사의 심리 적 피로도에 정(+)의 영향을 미치리란 것이었는데, 경 로모형에서 보듯이 이례상황 스트레스는 기관사의 심 리적 피로에 유의한 정 $(+)$ 의 영향을 미치는 것으로 나 타났다(.480). 따라서 가설 1 은 검증되었다.

가설 2 는 이례상황 스트레스의 증가가 기관사의 안 전행동 수준에 부(-)의 영향을 미치리란 것이었다. 경 로모형에서 보듯이 이례상황 스트레스의 증가는 안전 행동에 유의한 부(-)의 영향을 미치는 것으로 나타났다 (-.192), 따라서 가설 2 또한 검증되었다.

다음으로 가설 3 은 기관사의 심리적 피로도 증가가
안전행동에 부(-)의 영향을 미치리란 것이었다. 경로모 형에서 보듯이 기관사의 심리적 피로도 증가는 안전행 동에 유의한 부(-)의 영향을 미치는 것으로 나타났다 (-.422). 따라서 가설 3 또한 검증되었다.

마지막으로 가설 4 는 기관사의 안전 준수와 사고 간 에 부(-)의 관계가 있으리란 것이었는데, 경로모형에서 보듯이 기관사의 안전행동 수준은 사고에 유의한 부(-) 의 영향을 미치는 것으로 나타났다(-196). 따라서 가설 4 역시 검증되었다.

\section{3 논 의}

지금까지 선행연구에 대한 고찰을 배경으로 연구모 형과 가설을 설정하였다. 그리고 통계결과를 토대로 가 설검증을 수행하였다. 가설검증의 결과에 토대할 때 다 음의 논의가 가능하다.

첫째, 기관사가 경험하는 다양한 스트레스 요인 중에 서 본 연구의 주요 구성개념의 하나인 이례상황 스트레 스는 이례상황에 직면한 경우에만 국한되지 않고 향후 발생할지도 모를 미래상황에 대한 예기불안과도 관련이 있으며 책임사고에 따른 제도적 처벌과 불이익과도 관 련이 있다. 특히 사상사고의 경험이 있는 기관사는 외 상후 스트레스 장애(Post-Traumatic Stress Disorder) 로 인한 후유증으로 고통을 받는 경우가 적지 않다[3].

이례상황의 발생에 대한 이 같은 일상적이고 지속적 인 불안과 우려가 심리적 피로를 가져오리라는 것은 지극히 당연하며, 피로를 주제로 한 대부분의 연구문헌 은 피로에 의한 졸음, 의욕상실, 집중력 저하, 인지실패, 실수 등 여러 가지 부작용으로 인해 안전행동이 감소 하고 궁극적으로는 사고의 개연성을 높이는 결과를 야 기하는 것으로 보고하고 있다. 본 연구에서도 심리적 피로, 안전행동과 본인과실에 의한 사고 간에 유의한 인과관계가 있음이 밝혀졌다.

$<$ Table 5> Result of Path Analysis

\begin{tabular}{|c|c|c|c|c|}
\hline Path & $\begin{array}{c}\text { Coeffi- } \\
\text { cient }\end{array}$ & S.E & $\begin{array}{c}\mathrm{t}^{-} \\
\text {value }\end{array}$ & $\begin{array}{c}\mathrm{p}^{-} \\
\text {value }\end{array}$ \\
\hline \hline $\begin{array}{c}\text { Emergency Stress }-> \\
\text { Psychological fatigue }\end{array}$ & .480 & .077 & 6.699 & $.000^{* * *}$ \\
\hline $\begin{array}{c}\text { Emergency Stress -> } \\
\text { SBI }\end{array}$ & -.192 & .015 & -2.162 & $.031^{*}$ \\
\hline $\begin{array}{c}\text { Psy. Fatigue -> } \\
\text { SBI }\end{array}$ & -.422 & .014 & -4.823 & $.000^{* * *}$ \\
\hline $\begin{array}{c}\text { SBI -> } \\
\text { Accident by own fault }\end{array}$ & -.196 & .258 & -2.103 & $.035^{*}$ \\
\hline
\end{tabular}

$* * *=\mathrm{p}<0.001, * *=\mathrm{p}<0.01, *=\mathrm{p}<0.05$ 


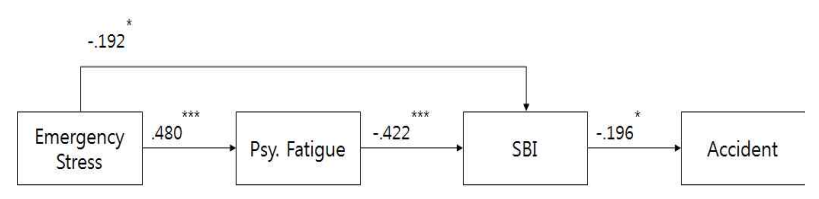

[Figure 2] Path Model

둘째, 연구모형에서 제시된 주요 구성개념 사이의 단 선적 인과관계를 포함한 전체 변인 간의 다원적 인과관 계를 보여주는 [Figure 2]의 경로모형을 살펴보면 이례 상황 스트레스는 심리적 피로 외에도 안전행동지수에 부(-)의 영향을 미치고 있다(-.192). 그러나 그 값이 단 선적 인과관계에 비해 작다는 사실에서 이례상황 스트 레스는 심리적 피로를 매개로 하여 안전행동에 영향을 미치고 있음을 알 수 있다. 따라서 이례상황 스트레스는 그 자체가 사고에 직접적인 영향을 미치는 요인은 아니 며 심리적 피로와 안전행동을 매개로 하여 사고에 영향 을 미친다고 할 수 있다. 결국 심리적 피로와 안전행동 은 이례상황 스트레스와 사고의 사이에서 매개역할을 하는 변인으로 볼 수 있다. 이를 검증하기 위해 간접효 과와 총효과를 분석해본 결과 통계적으로 유의하게 나 타났기 때문에 본 주장은 설득력이 있다고 볼 수 있다.

이 같은 결과는 기관사의 일상적 과업수행과정에서 경험하게 되는 각종 이례상황의 유형에 대한 체계적 접근과 함께, 이례상황으로 인해 유발되는 공포, 불안, 강박감, 긴장 등 제반 부정적 정서 및 스트레스의 유형 과 강도에 대한 과학적 연구의 필요성을 제기해준다. 이를 토대로 기관사가 경험하는 심리적 피로를 최대한 완화할 수 있는 조직차원의 지원방안이 마련될 필요가 있다. 이 같은 지원프로그램은 두 가지 방향에서 접근 이 가능한데, 그 하나는 일-삶의 균형(WLB: Work-

Life Balance)에 대한 제도적 지원이며, 다른 하나는 직 장 안에서의 심리적 안정을 도모할 수 있는 제도적 지 원이다. 전자는 가정에서의 충분한 휴식과 가족과의 원 만한 관계를 유지하도록 지원하는 것으로 삶 영역에서 의 원만한 관계와 충분한 휴식을 통한 재충전으로 스 트레스와 피로를 해소하는데 효과적이기 때문이다. 후 자의 경우는 직장내 상설 상담기구 및 심리치유 프로 그램의 운영과 과학적인 수면시설 등 각종 휴식시설의 설치와 운영 필요성을 제기한다.

\section{5. 결 론}

본 연구는 철도기관사의 인적오류를 주제로 기관사 의 이례상황 스트레스를 외생변인으로 설정하고 심리 적 피로 및 안전행동지수를 내생변인으로 설정하여 이 들 변인과 사고간의 관계를 실증적으로 분석해보려는
목적으로 수행되었다.

가설검증 결과, 이례상황 스트레스는 기관사의 심리 적 피로 증대와 유의한 관련이 있었으며, 기관사의 심 리적 피로는 다시 안전행동을 감소시키는 결과를 가져 온다는 것을 확인하였다. 그리고 안전행동과 사고를 주 제로 한 선행연구들의 결과와 같이 본 연구에서도 안 전행동은 사고에 유의한 부(-)의 영향을 미친다는 사실 이 확인되었다. 또한 이례상황 스트레스는 그 자체가 사고의 직접적 원인이 아니며 내생변인인 심리적 피로 와 안전행동지수를 매개로 하여 간접적으로 사고에 영 향을 미친다는 사실도 확인하였다.

이 같은 통계결과는 기관사들이 경험하는 이례상황 스트레스의 근본원인과 관리에 대한 조직차원의 접근 외에도 심리적 피로의 저감을 위한 체계적 관리의 필 요성을 제기하는 대목이다. 이는 안전행동의 제고를 위 해 필요한 전제조건인 동시에 궁극적으로 사고예방 및 저감에도 기여하기 때문이다.

본 연구는 단일기관의 기관사를 대상으로 수행된 만 큼, 본 연구의 결과를 일반화하는 데는 일정한 한계가 있다. 따라서 향후 여타의 철도기관을 포함한 확대연구 는 물론, 설문이라는 양적방법론의 한계를 보완하기 위 해 실험과 심층면접과 같은 질적 방법론을 적용한 연구 의 필요성도 있다. 본 연구는 이 같은 한계를 안고 있 음에도 기관사의 인적오류를 주제로 이례상황 스트레스 와 심리적 피로 및 안전행동지수를 주요 구성개념으로 설정하여 사고와의 관련성을 이들 변인 간의 역학관계 속에서 살펴보았다는 점에서 의의가 있다고 보겠다.

\section{References}

[1] KAERI, (2007), "Development of Regulatory Requirements for Managing Human Error and Evaluating the Aptitude of Safety-related Personnel", Ministry of Construction and Trans portation, Future Railway Technology Develop ment Project, 2nd year Report.

[2] J.Y.Yoon, (2013), "A Study on the Effect of Train Driver's Psychological Factors on Acci dents", Master Degree Dissertation, Seoul Na tional University of Science and Technology.

[3] Human Error Study Group, (2012), "Final Report on Human Error”, Korail, 156-262.

[4] Achieved at Wikipedia, (2013), "Stress (bio logy)", Retrieved on 28/10/2013.

[5] Y.M.Lee, T.H.Shin, M.K.Park, (2013), "The 
Effects of Health, Cognition, and Safety Climate on Safety Behavior and Accident : Focused on the Train Drivers", Journal of the Korean Society for Railway, 16(4), 331-339.

[6] S.T.Song, T.H.Shin, (2010), "A Study On The Interaction Between Internal Locus Of Control And Job Stress Of The Railway Drivers", Journal of Human Resource Management Re search, 17(3), 193-213.

[7] J.W.Jung, (2000), "The Role of Personality in Predicting Safety Performance: The Case of Railroad Officials Accident Involvement", Korean Journal of Industrial and Organizational Psycholo gy, 13(1), 41-60.

[8] W.Y.Lee, (2006), "The Interacting Effects of Cognitive Failure, Consciousness and Job Stress on Safety Behavior and Accidents", Korean Journal of Industrial and Organizational Psycholo gy, 19(3), 475-497.

[9] Y.S.Park, (2011), "Development of Safety Psycho logy Coaching Program", Research Report, KOSHA

[10] Achieved at SafetyNet, (2009), "Fatigue", retrieved on 31/10/2013.

[11] M.Cale et al, (2013), "Can you Know if Someone is too Tired to Drive safely?", in Rail Human Factors: Supporting reliablity, safety and cost reduction, edited by N.Dadashi et al, CRC Press, 347-353.

[12] D.Shinar, (2007), "Traffic Safety and Human Behavior", Emerald Group Publishing Limited, 73-74.

[13] A. Neal and M.A. Griffin, (2006), "A Study of the Lagged Relationships Among Safety Climate, Safety Motivation, Safety Behavior, and Accidents at the Individual and Group Levels", Journal of Applied Psychology, 91(4), 946-953.

[14] J.G.Jun, (2013), "Countermeasures to Mitigate Human Errors for Preventing KTX Driving Accidents", Doctoral Monograph, Graduate School of Railway, Seoul National University of Science and Technology.

[15] B.R.Bae, (2011), "Structural equation modeling with Amos 19 : principles and practice", CRBooks, Seoul.

[16] L.AHayduck, (1987), "Structural equation modeling with LISREL : essentials and advances", Baltimo re: Johns Hopkins University Press.
[17] B.S.Kim ME.Bae, (2010), "A Study on the influence of e-Service Quality of Internet Open-Market as Perceived Value, Customer Satisfaction and e-Loyalty", Journal of Korean Industrial Information Systems Society, 15(4), 83-101. 
저 자 소 개

김 승 태

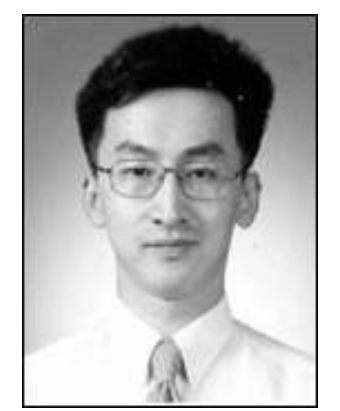

정보관리기술사를 보유하고, 서 울과학기술대학교 IT정책전문대 학교에서 석박사 통합과정을 수 료하였다. 현재 SK C\&C에 재 직 중이며, 주요 관심분야는 M\&A Process와 IT Convergence 등이다.

주소: 경기도 성남시 분당구 정자동 SK C\&C

신 택 현

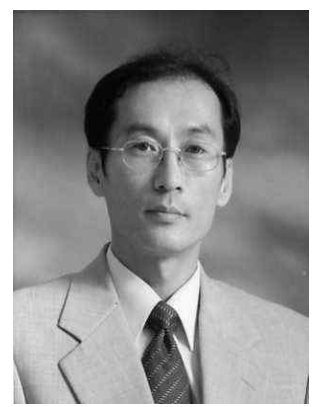

서울대학교에서 경영학 석사, 연 세대학교에서 경영학 박사 학위 를 취득하였다. 현재 서울과학기 술대학교 글로벌융합산업공학과 교수로 재직 중이며, 주요 관심 분야는 철도휴먼에러, 안전문화 등이다.

주소: 서울시 노원구 공릉 2 동 172 번지 서울과학기술대학교 글로벌융합산업공학과
이 용 만

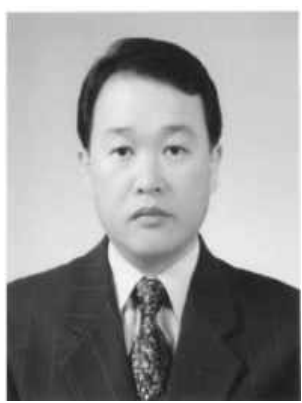

서울시립대학교 경영대학원에서 석사, 서울과학기술대학교 철도 전문대학원에서 박사과정을 수료 하였다. 현재 서울도시철도공사 에서 근무 중이며, 관심분야는 철도안전과 철도정책 분야이다.

주소: 서울시 노원구 공릉 2 동 172 번지 서울과학기술대학교 철도경영정책연구소

구 승 환

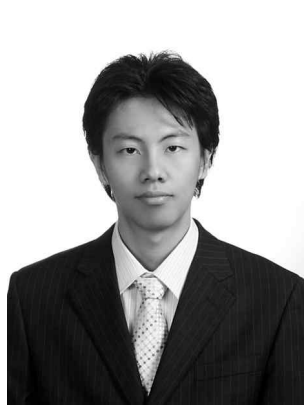

서울과학기술대학교에서 학사 및 공학석사를 취득하였으며, 서울 과학기술대학교 IT정책전문대학 원 박사과정을 수료하였다. 관심 분야는 $\mathrm{TOC}$ (제약경영), 데이터 사이언스 및 금융공학 등이다.

주소 서울시 노원구 공릉 2 동 172 번지 서울과학기술대학교 IT 정책전문대학원 